\title{
Sintesis Satu Langkah Senyawa Oksotrinuklir dengan Terminal Ligan Piridin $\left[\mathrm{Ru}_{3} \mathrm{O}\left(\mathrm{OOCC}_{6} \mathrm{H}_{5}\right)_{6}\left(\mathrm{C}_{5} \mathrm{H}_{5} \mathrm{~N}\right)_{3}\right] \mathrm{ClO}_{4}$
}

\author{
Aldes Lesbani*, Risfidian Mohadi, Eliza \\ Jurusan Kimia Fakultas Matematika dan Ilmu Pengetahuan Alam Universitas Sriwijaya \\ Jln. Raya Palembang Prabumulih Km. 32 Ogan Ilir 30662, Sumatera Selatan \\ *Email: aldeslesbani@yahoo.com
}

\begin{abstract}
Abstrak
Telah disintesis senyawa oksotrinuklir dengan terminal ligan piridin $\left[\mathrm{Ru}_{3} \mathrm{O}\left(\mathrm{OOCC}_{6} \mathrm{H}_{5}\right)_{6}\left(\mathrm{C}_{5} \mathrm{H}_{5} \mathrm{~N}\right)_{3}\right] \mathrm{ClO}_{4}$. Senyawa oksotrinuklir hasil sintesis dikarakterisasi menggunakan spektrofotometer FT-IR dan spektrometer massa. Hasil identifikasi dengan spektrofotometer FT-IR menunjukkan senyawa oksotrinuklir hasil sintesis memiliki vibrasi khas pada bilangan gelombang $698 \mathrm{~cm}^{-1}$. Pengukuran menggunakan spektrometer massa menkonfirmasi bahwa senyawa oksotrinuklir memiliki ligan terminal piridin yang mudah terfragmentasi yang ditandai dengan puncak ion molekul pada $m / z$ 1283,14 dan puncak ion fragmen pada $m / z$ 1205,09 yang mengindikasikan lepasnya satu molekul piridin sebagai terminal ligan.
\end{abstract}

Kata kunci : senyawa oksotrinuklir, sintesis satu langkah, ruthenium, piridin.

\begin{abstract}
Synthesis of oxotrinuclear with pyridine as terminal ligand $\left[\mathrm{Ru}_{3} \mathrm{O}\left(\mathrm{OOCC}_{6} \mathrm{H}_{5}\right)_{6}\left(\mathrm{C}_{5} \mathrm{H}_{5} \mathrm{~N}\right)_{3}\right] \mathrm{ClO}_{4}$ has been carried out. Oxotrinuclear compound from synthesis was characterized using FT-IR spectrophotometer and mass spectrometer. The FTIR spectrum shows that oxotrinuclear compound has vibration at wavelength $698 \mathrm{~cm}^{-1}$ and mass spectrometer spectrum shows oxotrinuclear compound has pyridine as terminal ligand which easily fragmented indicated by molecular ion peak at $\mathrm{m} / \mathrm{z}, 1283.14$ and ion fragment peak at $\mathrm{m} / \mathrm{z}, 1205.09$. These values revealed one molecule of pyridine lost from terminal ligand.
\end{abstract}

Keywords : oxotrinuclear compound, one step synthesis, ruthenium, pyridine.

\section{PENDAHULUAN}

Senyawa-senyawa oksotrinuklir dengan rumus umum $\left[\mathrm{M}_{3}(\mathrm{O})(\mathrm{OOCR})_{6}(\mathrm{~L})_{3}\right]^{\mathrm{Z}+}$ seperti yang tersaji pada Gambar 1 hingga saat ini terus diteliti dan disintesis guna berbagai keperluan. Salah satu manfaat senyawa oksotrinuklir yakni sebagai material magnet dan material sensor (Castro et.al, 1996, An et.al, 1999). Lesbani (2008) melaporkan bahwa senyawa oksotrinuklir dapat pula digunakan sebagai makrokation dalam rangka sintesis nanokristal ionik dengan kombinasi menggunakan makroanion. Nanokristal ionik yang dihasilkan dapat digunakan sebagai katalis maupun sebagai material nanoseparation untuk memisahkan molekulmolekul yang tidak bisa dipisahkan dengan material biasa maupun secara reaksi kimia (Jiang et.al, 2006).

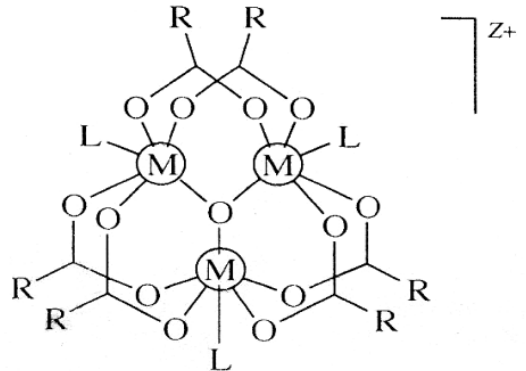

Gambar 1. Senyawa oksotrinuklir dengan rumus umum $\left[\mathrm{M}_{3}(\mathrm{O})(\mathrm{OOCR})_{6}(\mathrm{~L})_{3}\right]^{\mathrm{Z}+}(\mathrm{M}=$ atom pusat, $\mathrm{R}=$ gugus organik, $\mathrm{L}=$ terminal ligan, $\mathrm{Z}=$ muatan senyawa oksotrinuklir

Sintesis senyawa-senyawa oksotrinuklir pada umumnya dilakukan secara sederhana dengan beberapa tahap maupun satu tahap sintesis. Sintesis dilakukan dengan 
memodifikasi ligan maupun atom pusat yang terikat serta mengganti ligan-ligan terminal pada senyawa oksotrinuklir tersebut. Lesbani dkk (2012) melaporkan sintesis dan karakteriasi senyawa oksotrinuklir $\left[\mathrm{Ru}_{2} \mathrm{Co}(\mathrm{O})\right.$ $\left.\left(\mathrm{OOCCH}_{3}\right)_{6}\left(\mathrm{C}_{5} \mathrm{H}_{5} \mathrm{~N}\right)_{3}\right]\left(\mathrm{ClO}_{4}\right)$ yang merupakan senyawa trinuklir dengan campuran valensi dan atom yakni ruthenium dan kobalt. Senyawa ini telah berhasil dikarakterisasi menggunakan spektroskopi massa dan spektroskopi FT-IR yang menunjukkan adanya campuran atom pada atom trinuklir. Senyawa oksotrinuklir dengan atom kobalt secara terpisah telah disintesis oleh Sumner and Steinmetz (1985). Senyawa oksotrinuklir ruthenium $\quad\left[\mathrm{Ru}_{3}(\mathrm{O})\left(\mathrm{OOCCH}_{3}\right)_{6}\left(\mathrm{H}_{2} \mathrm{O}\right)_{3}\right]$ $\left(\mathrm{OCOCH}_{3}\right)$ telah dilaporkan oleh Fouda and Rempel (1979) dan senyawa ini dapat dengan mudah disintesis mengggunakan metoda sintesis satu langkah. Akan tetapi ligan-ligan terminal yang digunakan merupakan ligan netral yang umumnya adalah air. Penggantian ligan terminal yang berupa air dengan ligan organik dalam rangka modifikasi struktur merupakan tema yang menarik dalam rangka mencari keragaman senyawa-senyawa oksotrinuklir.

Pada penelitian ini disintesis senyawa oksotrinuklir dengan terminal ligan piridin yakni $\quad\left[\mathrm{Ru}_{3} \mathrm{O}\left(\mathrm{OOCC}_{6} \mathrm{H}_{5}\right)_{6}\left(\mathrm{C}_{5} \mathrm{H}_{5} \mathrm{~N}\right)_{3}\right] \mathrm{ClO}_{4}$ dengan sintesis satu langkah dengan mengganti air sebagai terminal ligan dengan piridin. Penggantian air sebagai terminal ligan menjadi piridin diharapkan dapat meningkatkan kelarutan senyawa oksotrinuklir $\left[\mathrm{Ru}_{3} \mathrm{O}\left(\mathrm{OOCC}_{6} \mathrm{H}_{5}\right)_{6}\left(\mathrm{C}_{5} \mathrm{H}_{5} \mathrm{~N}\right)_{3}\right] \mathrm{ClO}_{4} \quad$ dalam pelarut organik sehingga pemanfaatannya sebagai makrokation dalam sintesis nanokristal ionik dapat dilakukan secara optimal. Proses identifikasi senyawa oksotrinuklir hasil sintesis dilakukan dengan menggunakan spektrofotometer FT-IR dan spektrometer massa.

\section{METODOLOGI PENELITIAN}

\section{Alat dan Bahan}

Peralatan yang digunakan dalam penelitian ini meliputi peralatan gelas kimia standar. Karakterisasi senyawa hasil sintesis mengunakan spektrofotometer FTIR Jasco dan spektrometer massa perkin Elmer TurboMass. Analisis senyawa oksotrinuklir dengan spektrofotometer FTIR dengan pelet $\mathrm{KBr}$ dan sampel di scan pada rentang bilangan gelombang 250-4000 $\mathrm{cm}^{-1}$. Analisis dengan spektrometer massa sampel terlebih dahulu dilarutkan dalam asetonitril.

Bahan-bahan kimia yang digunakan dalam penelitian ini berkualitas analytical grade buatan TCI, Kanto dan Merck yang digunakan langsung tanpa pemurnian lebih lanjut yang meliputi asam benzoat, natrium hidroksida, etanol, ruthenium klorida, metanol, piridin, ammonium perklorat. Air yang digunakan dalam proses sintesis merupakan air bebas mineral yang diperoleh dari proses pemurnian dengan resin penukar ion.

\section{Prosedur sintesis senyawa oksotrinuklir $\left[\mathrm{Ru}_{3} \mathrm{O}\left(\mathrm{OOCC}_{6} \mathrm{H}_{5}\right)_{6}\left(\mathrm{C}_{5} \mathrm{H}_{5} \mathrm{~N}\right)_{3}\right] \mathrm{ClO}_{4}$ dan karakterisasinya}

Prosedur sintesis satu langkah senyawa oksotrinuklir $\left[\mathrm{Ru}_{3} \mathrm{O}\left(\mathrm{OOCC}_{6} \mathrm{H}_{5}\right)_{6}\right.$ $\left.\left(\mathrm{C}_{5} \mathrm{H}_{5} \mathrm{~N}\right)_{3}\right] \mathrm{ClO}_{4}$ dilakukan atas prosedur yang diperkenalkan oleh Almog et.al (1993) dan Sasaki et.al (1993) dengan adanya sedikit modifikasi pada proses penggantian terminal ligan air dengan piridin yakni sebagai berikut: sebanyak $47 \mathrm{~g}$ asam benzoat dan 1,6 $\mathrm{g}$ natrium hidroksida dimasukkan kedalam beaker gelas $250 \mathrm{~mL}$ yang telah dilengkapi dengan pengaduk magnetik. Sebanyak $150 \mathrm{~mL}$ etanol lalu ditambahkan secara perlahan kedalam beaker gelas tersebut sambil diaduk secara merata. Campuran kemudian dipanaskan pada temperatur $50{ }^{\circ} \mathrm{C}$ sampai semua campuran larut dan homogen. Sebanyak $1 \mathrm{~g}$ ruthenium klorida ditambahkan kedalam larutan tadi dan campuran dipindahkan kedalam labu $250 \mathrm{~mL}$ untuk dilakukan refluk selama 1 jam. Larutan yang diperoleh berwarna biru kehijauan. Larutan yang diperoleh kemudian dievaporasi dan ditambahkan $100 \mathrm{~mL}$ metanol dan $1 \mathrm{~mL}$ piridin. Setelah penambahan metanol dan piridin maka larutan kembali direfluk selama 1 jam. Setelah proses refluk selesai maka larutan dipindahkan kedalam beaker gelas $250 \mathrm{~mL}$ yang dilengkapi dengan pengaduk magnetik. Kedalam larutan tersebut ditambahkan $0,5 \mathrm{~g}$ ammonium perklorat dan larutan didiamkan semalam dalam lemari pendingin. Setelah itu diperoleh padatan biru tua yang kemudian disaring dan dicuci dengan air bebas mineral dan dikeringkan. Padatan kering merupakan senyawa oksotrinuklir $\left[\mathrm{Ru}_{3} \mathrm{O}\left(\mathrm{OOCC}_{6} \mathrm{H}_{5}\right)_{6}\right.$ $\left.\left(\mathrm{C}_{5} \mathrm{H}_{5} \mathrm{~N}\right)_{3}\right] \mathrm{ClO}_{4}$ yang siap dikarakterisasi. 


\section{HASIL DAN PEMBAHASAN}

Senyawa oksotrinuklir $\quad\left[\mathrm{Ru}_{3} \mathrm{O}\right.$ $\left.\left(\mathrm{OOCC}_{6} \mathrm{H}_{5}\right)_{6}\left(\mathrm{C}_{5} \mathrm{H}_{5} \mathrm{~N}\right)_{3}\right] \mathrm{ClO}_{4}$ dengan terminal ligan piridin merupakan turunan dari senyawa oksotrinuklir $\quad\left[\mathrm{Ru}_{3} \mathrm{O}\left(\mathrm{OOCC}_{6} \mathrm{H}_{5}\right)_{6}\left(\mathrm{H}_{2} \mathrm{O}\right)_{3}\right] \mathrm{X}$ dimana $\mathrm{X}$ adalah anion bermuatan satu. Dengan teknik sintesis satu langkah melalui penambahan piridin sebagai pengganti air dengan metanol maka dapat diperoleh senyawa okstotrinuklir dengan terminal ligan piridin. Konsep ini merupakan analog terhadap senyawa oksotrinuklir kromium yakni $\left[\mathrm{Cr}_{3} \mathrm{O}\left(\mathrm{OOCC}_{6} \mathrm{H}_{5}\right)_{6}\left(\mathrm{C}_{5} \mathrm{H}_{5} \mathrm{~N}\right)_{3}\right] \mathrm{ClO}_{4}$ yang berasal dari $\left[\mathrm{Cr}_{3} \mathrm{O}\left(\mathrm{OOCC}_{6} \mathrm{H}_{5}\right)_{6}\left(\mathrm{H}_{2} \mathrm{O}\right)_{3}\right] \mathrm{ClO}_{4}$ (Harton et.al, 1994). Senyawa oksotrinuklir hasil sintesis yakni $\left[\mathrm{Ru}_{3} \mathrm{O}\left(\mathrm{OOCC}_{6} \mathrm{H}_{5}\right)_{6}\right.$ $\left.\left(\mathrm{C}_{5} \mathrm{H}_{5} \mathrm{~N}\right)_{3}\right] \mathrm{ClO}_{4}$ yang berwarna biru tua diperoleh sebanyak $0.45 \mathrm{~g}$.

Piridin sebagai terminal ligan dalam senyawa oksotrinuklir diketahui mempunyai kelarutan yang rendah dalam air sehingga menarik untuk disintesis. Senyawa oksotrinuklir yang diperoleh dalam penelitian ini yakni $\left[\mathrm{Ru}_{3} \mathrm{O}\left(\mathrm{OOCC}_{6} \mathrm{H}_{5}\right)_{6}\left(\mathrm{C}_{5} \mathrm{H}_{5} \mathrm{~N}\right)_{3}\right] \mathrm{ClO}_{4}$ juga tidak larut dalam pelarut air. Beberapa pelarut yang digunakan untuk melarutkan senyawa oksotrinuklir $\left[\mathrm{Ru}_{3} \mathrm{O}\left(\mathrm{OOCC}_{6} \mathrm{H}_{5}\right)_{6}\right.$ $\left.\left(\mathrm{C}_{5} \mathrm{H}_{5} \mathrm{~N}\right)_{3}\right]_{\mathrm{ClO}_{4}}$ yang diujikan yakni metanol, etanol, aseton, astonitril serta air. Dari pelarutpelarut tersebut hanya air yang tidak dapat melarutkan senyawa oksotrinuklir $\left[\mathrm{Ru}_{3} \mathrm{O}\left(\mathrm{OOCC}_{6} \mathrm{H}_{5}\right)_{6}\left(\mathrm{C}_{5} \mathrm{H}_{5} \mathrm{~N}\right)_{3}\right] \mathrm{ClO}_{4}$ sedangkan pelarut lainnya dapat melarutkan dengan baik. Hal ini menunjukkan bahwa pelarut-pelarut organik merupakan pelarut yang cocok untuk melarutkan senyawa oksotrinuklir dengan terminal ligan piridin.

Senyawa oksotrinuklir hasil sintesis kemudian dikarakterisasi dengan menggunakan spektrofotometer FTIR dan spektrometer massa. Penggunaan spektrofotometer FTIR dalam analisis senyawa oksotrinuklir telah dilakukan secara intensif yang menghasilkan kesimpulan rentang bilangan gelombang spesifik untuk senyawa oksotrinuklir (Ohto et.al, 1995). Hal ini menunjukkan bahwa langkah awal identifikasi senyawa oksotrinuklir yang harus dilakukan dalam proses karakterisasi yakni menggunakan spektrofotometer FTIR. Spektra FTIR senyawa oksotrinuklir hasil sintesis $\left[\mathrm{Ru}_{3} \mathrm{O}\left(\mathrm{OOCC}_{6} \mathrm{H}_{5}\right)_{6}\left(\mathrm{C}_{5} \mathrm{H}_{5} \mathrm{~N}\right)_{3}\right] \mathrm{ClO}_{4}$ disajikan pada Gambar 2.

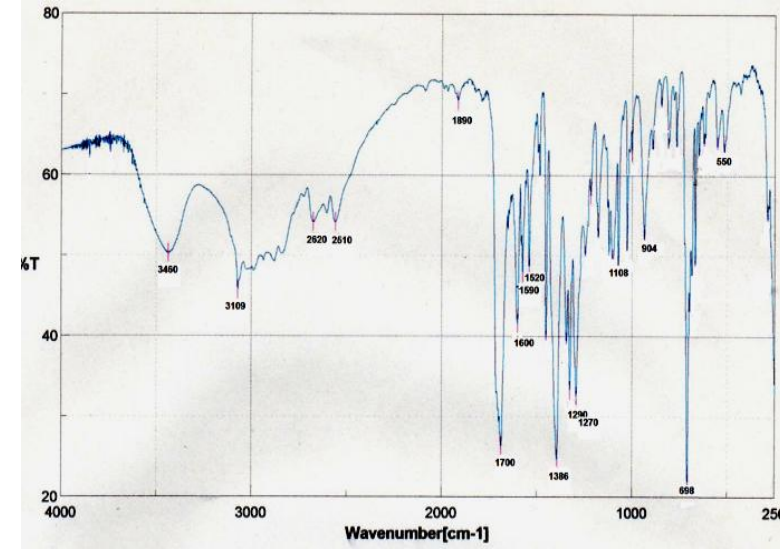

Gambar 2. Spektra FT-IR senyawa oksotrinuklir $\left[\mathrm{Ru}_{3} \mathrm{O}\left(\mathrm{OOCC}_{6} \mathrm{H}_{5}\right)_{6}\left(\mathrm{C}_{5} \mathrm{H}_{5} \mathrm{~N}\right)_{3}\right] \mathrm{ClO}_{4}$

Pada Gambar 2 terlihat bahwa bilangan gelombang spesifik yang menunjukkan adanya jembatan ruthenium oksigen $\left(\mu_{3}-\mathrm{O}-\mathrm{Ru}\right)$ teridentifikasi pada bilangan gelombang 698 $\mathrm{cm}^{-1}$ (Johnson et.al, 1981). Walaupun terminal ligan dipertukarkan dengan molekul-molekul lainnya akan tetapi jembatan metal oksigen $\left(\mu_{3}-\mathrm{O}-\mathrm{M}\right)$ tidak memberikan pengaruh yang besar terhadap pergeseran bilangan gelombang spesifik yang dimiliki oleh senyawa oksotrinuklir sehingga vibrasi jembatan metal oksigen pada senyawa oksotrinuklir $\left[\mathrm{Ru}_{3} \mathrm{O}\left(\mathrm{OOCC}_{6} \mathrm{H}_{5}\right)_{6}\left(\mathrm{C}_{5} \mathrm{H}_{5} \mathrm{~N}\right)_{3}\right] \mathrm{ClO}_{4}$ dan

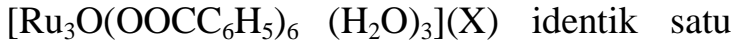
sama lain.

Vibrasi lainnya yang muncul pada bilangan gelombang disekitar $1600 \mathrm{~cm}^{-1}$ menunjukkan adanya gugus aromatik yang merupakan gugus benzil yang terdapat pada senyawa oksotrinuklir hasil sintesis yang diperkuat dengan adanya piridin sebagai terminal ligan (Solomons and Fryhle, 2008). Hasil identifikasi menggunakan spektrofotometer FTIR terhadap senyawa oksotrinuklir $\quad\left[\mathrm{Ru}_{3} \mathrm{O}\left(\mathrm{OOCC}_{6} \mathrm{H}_{5}\right)_{6}\left(\mathrm{C}_{5} \mathrm{H}_{5} \mathrm{~N}\right)_{3}\right]$ $\mathrm{ClO}_{4}$ menunjukkan senyawa oksotrinuklir dengan ligan piridin telah berhasil disintesis.

Karakterisasi senyawa hasil sintesis selanjutnya dilakukan dengan pengukuran spektrometer massa. Bergen et.al (1993) melaporkan analisis senyawa oksotrinulir $\left[\mathrm{M}_{3} \mathrm{O}(\mathrm{RCOO})_{6}(\mathrm{~L})_{3}\right]^{+}\left(\mathrm{M}=\mathrm{Cr}, \mathrm{Fe} ; \mathrm{L}=\mathrm{H}_{2} \mathrm{O}\right.$, $\mathrm{MeOH}$, py) menggunakan teknik electrospray ionization menghasilkan puncak-puncak ion fragmen dari molekul oksotrinuklir. Hasil analisis ini menunjukkan bahwa senyawa oksotrinuklir yang dianalisis dengan spectrometer massa akan mengalami 


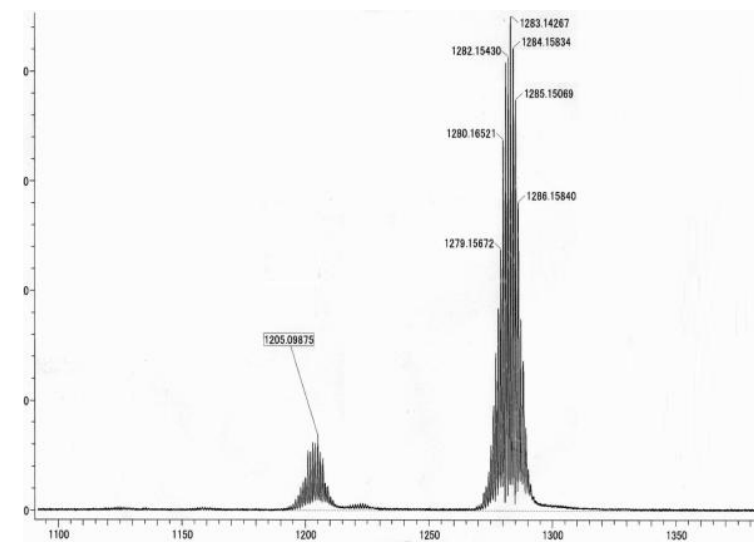

Gambar 3. Spektra massa senyawa oksotrinuklir $\left[\mathrm{Ru}_{3} \mathrm{O}\left(\mathrm{OOCC}_{6} \mathrm{H}_{5}\right)_{6}\left(\mathrm{C}_{5} \mathrm{H}_{5} \mathrm{~N}\right)_{3}\right] \mathrm{ClO}_{4}$

fragmentasi menjadi ion-ion fragmen penyusun senyawa oksotrinuklir. Spektra massa senyawa oksotrinuklir $\left[\mathrm{Ru}_{3} \mathrm{O}\left(\mathrm{OOCC}_{6} \mathrm{H}_{5}\right)_{6}\left(\mathrm{C}_{5} \mathrm{H}_{5} \mathrm{~N}\right)_{3}\right] \mathrm{ClO}_{4}$ disajikan pada Gambar 3.

Proses pengionisasian dilakukan dengan sistem cold spray ionization dimana sampel senyawa oksotrinuklir $\left[\mathrm{Ru}_{3} \mathrm{O}\left(\mathrm{OOCC}_{6} \mathrm{H}_{5}\right)_{6}\right.$ $\left.\left(\mathrm{C}_{5} \mathrm{H}_{5} \mathrm{~N}\right)_{3}\right] \mathrm{ClO}_{4}$ dilarutkan terlebih dahulu menggunakan asetonitril sebagai pelarut. Pada Gambar 3 terlihat bahwa puncak ion molekul teridentifikasi pada pengukuran yakni pada $\mathrm{m} / \mathrm{z}$ 1283,14 dengan intensitas yang tinggi. Puncak ion molekul tersebut muncul dengan beberapa puncak lainnya berdempetan dengan selisih 14. Hal ini menunjukkan bahwa atom ruthenium memiliki beberapa isotop yang menyebabkan pengukuran menggunakan spektrometer massa menghasilkan puncak-puncak ion molekul yang berdempetan. Isotop ruthenium yang stabil yakni 101,07 muncul pada pengukuran yang menghasilkan nilai $\mathrm{m} / \mathrm{z} \quad 1238,14$. Selanjutnya terdapat puncak ion fragmen pada $\mathrm{m} / \mathrm{z}$ 1205,09 yang merupakan hasil fragmentasi satu molekul piridin sebagai terminal ligan. Sama halnya dengan puncak ion molekul pada $\mathrm{m} / \mathrm{z}$ 1283,14 yang memiliki puncak yang berdempetan sebagai efek isotop ruthenium maka pada puncak ion fragmen $\mathrm{m} / \mathrm{z}$ 1205,09 juga muncul puncak yang berdempetan. Pengukuran terhadap senyawa oksotrinuklir hasil sintesis $\left[\mathrm{Ru}_{3} \mathrm{O}\left(\mathrm{OOCC}_{6} \mathrm{H}_{5}\right)_{6}\left(\mathrm{C}_{5} \mathrm{H}_{5} \mathrm{~N}\right)_{3}\right]$ $\mathrm{ClO}_{4}$ sesuai dengan analisis yang dilakukan oleh Bergen et.al yang menyatakan bahwa senyawa oksotrinuklir mengalami fragmentasi pada pengukuran menggunakan spektrometer massa. Hasil pengukuran menggunakan spektrometer massa ini menunjukkan bahwa senyawa oksotrinuklir $\left[\mathrm{Ru}_{3} \mathrm{O}\left(\mathrm{OOCC}_{6} \mathrm{H}_{5}\right)_{6}\right.$ $\left.\left(\mathrm{C}_{5} \mathrm{H}_{5} \mathrm{~N}\right)_{3}\right] \mathrm{ClO}_{4}$ yang memiliki terminal ligan piridin telah berhasil disintesis dengan satu tahap sintesis.

\section{SIMPULAN}

Senyawa oksotrinuklir dengan terminal ligan piridin $\left[\mathrm{Ru}_{3} \mathrm{O}\left(\mathrm{OOCC}_{6} \mathrm{H}_{5}\right)_{6}\left(\mathrm{C}_{5} \mathrm{H}_{5} \mathrm{~N}\right)_{3}\right] \mathrm{ClO}_{4}$ telah berhasil disintesis dengan proses satu langkah sebanyak 0,45 g yang merupakan padatan berwarna biru tua. Karakterisasi dengan spektrofotometer FTIR menunjukkan ciri khas senyawa oksotrinukir teridentifikasi pada bilangan gelombang $698 \mathrm{~cm}^{-1}$. Spektrum massa senyawa oksotrinuklir $\left[\mathrm{Ru}_{3} \mathrm{O}\left(\mathrm{OOCC}_{6} \mathrm{H}_{5}\right)_{6}\left(\mathrm{C}_{5} \mathrm{H}_{5} \mathrm{~N}\right)_{3}\right] \mathrm{ClO}_{4}$ menunjukkan puncak ion molekul fragmentasi pada $\mathrm{m} / \mathrm{z}$ 1283,14 dan 1205,09 yang mengindikasikan lepasnya fragmen piridin sebagai terminal ligan dalam proses pengukuran.

\section{UCAPAN TERIMA KASIH}

Disampaikan kepada Prof. N. Mizuno, The University of Tokyo atas penggunaan spektrometer massa.

\section{DAFTAR PUSTAKA}

An. J, Chen. Z.D, Bian. J, Jin. X.L, Wang. S.X, Xu. G.X, 1999, Synthesis, Crystal Structures and Magnetic properties of Trinuclear Oxocentered Manganese Complexes of the General Formula $\left[\mathrm{Mn}_{3} \mathrm{O}\left(\mathrm{O}_{2} \mathrm{CR}\right)_{6} \mathrm{~L}_{3}\right]^{\mathrm{z+}}(\mathrm{R}=$ $\mathrm{Me}, \mathrm{Et}, \mathrm{Ph}, \mathrm{CH}_{2} \mathrm{Cl}, \mathrm{L}=3$-methylpyridine or water $\mathrm{Z}=1,0$ ), Inorg. Chim. Acta, 287, 8288 .

Almog. O, Bino. A, Garfinkel-Shweky. D, 1993, The Structure of Oxo-Bridged Trinuclear Ruthenium and Iridium Hexacarboxylate, Inorg. Chim. Acta, 213, 99-102.

Bergen. A.V.D, Colton. R, Percy. M, West. B.O, 1993, Electrospray Mass Spectrometric Study of $\left[\mathrm{M}_{3} \mathrm{O}(\mathrm{RCOO})_{6}(\mathrm{~L})_{3}\right]^{+}$Cations $(\mathrm{M}=$ $\mathrm{Cr}, \mathrm{Fe} ; \mathrm{L}=\mathrm{H}_{2} \mathrm{O}, \mathrm{MeOH}$, py), Inorg. Chem, 32, 3408-3411.

Castro. S.L, Streib. W.E, Sun. J.S, Christou. G, 1996, Structural, Spectroscopic, and Magnetochemical Characterization of the Trinuclear Vanadium(III) carboxylates $\left[\mathrm{V}_{3} \mathrm{O}\left(\mathrm{O}_{2} \mathrm{CR}\right)_{6} \mathrm{~L}_{3}\right]\left(\mathrm{ClO}_{4}\right) \quad(\mathrm{R}=\quad$ Various Groups; L= Pyridine, 4-Picoline, 3,5Lutidine), Inorg. Chem, 35, 4462-4468.

Fouda. S.A, Rempel. G.L, 1979, $\mu_{3}$-OxоTriruthenium Acetate Cluster Complexes as Catalysts For Olefin Hydrogenation, Inorg. Chem, 18, 1-8.

Harton. A, Nagi. M.K, Glass. M.M, Junk. P.C, 
Atwood. J.L, Vincent. J.B, 1994, Synthesis and Characterization of Symmetric and Unsymmetric Oxo-Bridged Trinuclear Chromium Benzoate Complexes: Crystal and Molecular Structure of $\left[\mathrm{Cr}_{3} \mathrm{O}\left(\mathrm{O}_{2} \mathrm{CPh}\right)_{6}(\mathrm{py})_{3}\right] \mathrm{ClO}_{4}$, Inorg. Chim. Acta, 217, 171-179.

Jiang. C, Lesbani. A, Kawamoto. R, Uchida. S, Mizuno. N, 2006, Channel-Selective Independent Sorption and Collection of Hydrophilic and Hydrophobic Molecules by $\mathrm{Cs}_{2}\left[\mathrm{Cr}_{3} \mathrm{O}\left(\mathrm{OOCC}_{2} \mathrm{H}_{5}\right)_{6}\left(\mathrm{H}_{2} \mathrm{O}\right)_{3}\right]_{2}\left[\alpha-\mathrm{SiW}_{12} \mathrm{O}_{40}\right]$ Ionic Crystal, J. Am. Chem. Soc, 128, 14240-14241.

Johnson. M.K, Powell. D.B, Cannon. R.D, 1981, Vibrational Spectra of Carboxylato Complexes-III. Trinuclear 'Basic' Acetates and Formates of Chromium(III), Iron (III) And Other Transition Metals, Spectro. Chim. Acta, 37A, 11, 995-1006.

Lesbani. A, Kawamoto. R, Uchida. S, Mizuno. N, 2008, Control of Structure and Sorption Properties of Ionic Crystals of $\mathrm{A}_{2}\left[\mathrm{Cr}_{3} \mathrm{O}\left(\mathrm{OOCC}_{2} \mathrm{H}_{5}\right)_{6}\left(\mathrm{H}_{2} \mathrm{O}\right)_{3}\right]_{2}\left[\alpha-\mathrm{SiW}_{12} \mathrm{O}_{40}\right]$ $(\mathrm{A}=\mathrm{Na}, \mathrm{K}, \mathrm{Rb}, \mathrm{NH} 4, \mathrm{Cs}, \mathrm{TMA})$, Inorg. Chem, 47, 3349-3357.
Lesbani. A, Mohadi. R, Hidayati. N, 2012, Sintesis dan Karakterisasi Senyawa Oksotrinuklir $\left[\mathrm{Ru}_{2} \mathrm{Co}(\mathrm{O})\left(\mathrm{OOCCH}_{3}\right)_{6}\left(\mathrm{C}_{5} \mathrm{H}_{5} \mathrm{~N}\right)_{3}\right]\left(\mathrm{ClO}_{4}\right)$, Jurnal Kimia, FMIPA Universitas Udayana, 6, 110-114.

Ohto. A, Yamamoto. A.T, Abe. M, Ito. T, Sasaki. Y, Umakoshi. K, Cannon. R.D, 1995, Structure and Vibrational Spectra of Trinuclear Metal Cluster Complexes. A Question of Symmetry, Chem. Lett, 2, 9798.

Sasaki. Y, Nagasawa. A, Yamamoto. A.T, Ito. T, 1993, Substitution of Methanol-d $\mathrm{d}_{4}$ For the Coordinated water in the Trinuclear Complexes, $\quad\left[\mathrm{M}_{3}\left(\mu_{3}-\mathrm{O}\right)\left(\quad \mu_{3-}\right.\right.$ $\left.\left.\mathrm{CH}_{3} \mathrm{COO}\right)_{6}\left(\mathrm{H}_{2} \mathrm{O}\right)_{3}\right]^{+} \quad\left(\mathrm{M}=\mathrm{Ru}_{3}, \quad \mathrm{Rh}_{3}, \quad\right.$ or $\mathrm{Ru}_{2} \mathrm{Rh}$ ) in Methanol-d $\mathrm{d}_{4}$, Inorg. Chim. Acta, 212, 175-182.

Solomons. T.W.G, Fryhle. C.B, 2008, Organic Chemistry $9^{\text {th }}$ Edition, John Wiley \& Sons, Inc, USA.

Sumner. C.E, Steinmetz. G.R, 1985, Isolation of Oxo-Centered Cobalt(III) Clusters and Their Role in the Cobalt bromine Catalyzed Autoxidation of Aromatic Hydrocarbons, $J$. Am. Chem. Soc, 107, 6124-6126. 